\title{
Landiolol and esmolol prevent tachycardia with- out altering cerebral blood flow
}

\author{
[Le landiolol et l'esmolol préviennent la tachycardie sans altérer le débit sanguin \\ cérébral]
}

\author{
Shigeru Saito MD, ${ }^{*}$ Fumio Nishihara MD, ${ }^{*}$ Tomioka Akihiro MD, ${ }^{*}$ Koichi Nishikawa MD, ${ }^{*}$ Hideaki Obata MD, ${ }^{*}$ \\ Fumio Goto MD, ${ }^{*}$ Naoya Yuki MD $†$
}

Purpose: Several B-adrenergic-blocking drugs have been used during electroconvulsive therapy (ECT) to stabilize the hemodynamic alterations following electrical stimulation. The effects of two ultra-short acting B-adrenergic-blocking drugs, esmolol and landiolol, on systemic and cerebral circulation were studied during ECT.

Methods: In the first study $(n=15)$, dose-dependent hemodynamic changes were studied when landiolol was administered immediately after induction of anesthesia. In the second study $(n=12)$, effects of esmolol and landiolol on systemic and cerebral circulation were compared. Patients in Study I received three doses of landiolol, and patients in Study 2 received two types of $\mathrm{B}$-adrenergic-blocking drugs, in a randomized crossover design in a series of ECT trials.

Results: In the first study, 0.25 to $0.5 \mathrm{mg} \cdot \mathrm{kg}^{-1}$ landiolol induced a lower heart rate after the electrical stimulation compared to vehicle $(P<0.01)$. Landiolol did not have significant effects on blood pressure. In the second study, heart rate was stabilized by $1.0 \mathrm{mg} \cdot \mathrm{kg}^{-1}$ esmolol iv or $0.5 \mathrm{mg} \cdot \mathrm{kg}^{-1}$ landiolol iv. Increase in mean blood pressure was ameliorated by esmolol $(P<0.0 \mathrm{I})$, but not by landiolol. Mean cerebral blood flow velocity in the middle cerebral artery increased at one to two minutes after the electrical stimulation regardless of the use of B-adrenergicblocking drugs $(P<0.01)$. Muscular and electroencephalographic seizure durations were not significantly altered by the B-adrenergic-blocking drugs.

Conclusion: Landiolol suppresses heart rate elevation during ECT without affecting blood pressure. Cerebral blood flow velocity in the middle cerebral artery is not affected by the use of either esmolol or landiolol.
Objectif: Certains B-bloquants ont été utilisés pendant la sismothérapie pour stabiliser les changements hémodynamiques qui suivent la stimulation électrique. Les effets de deux B-bloquants à action ultracourte sur la circulation générale et cérébrale, l'esmolol et le landiolol, ont été étudiés pendant la sismothérapie.

Méthode: Dans la $I^{\mathrm{e}}$ étude $(n=15)$, les changements hémodynamiques reliés à la dose ont été étudiés quand le landiolol est administré immédiatement après l'induction de l'anesthésie. Dans la $2^{\mathrm{e}}$ étude $(n=12)$, les effets de l'esmolol et du landiolol sur la circulation générale et cérébrale ont été comparés. Les patients de la $I^{\mathrm{e}}$ étude ont reçu trois doses de landiolol et ceux de la $2^{\mathrm{e}}$, deux types de $\beta$-bloquants d'une façon randomisée et croisée dans une série d'épreuves de sismothérapie.

Résultats: Dans la le étude, de 0,25 à 0,5 $\mathrm{mg} \cdot \mathrm{kg}^{-1}$ de landiolol, comparé au véhicule, ont fait baisser la fréquence cardiaque après la stimulation électrique $(P<0,0 I)$. Le landiolol n'a pas eu d'effet significatif sur la tension artérielle. Dans la $2^{\mathrm{e}}$ étude, la fréquence cardiaque a été stable avec $1,0 \mathrm{mg} \cdot \mathrm{kg}^{-1}$ d'esmolol iv ou $0,5 \mathrm{mg} \cdot \mathrm{kg}^{-1}$ de landiolol iv. La hausse de la tension artérielle moyenne a été corrigée par l'esmolol $(P<0,01)$, mais non par le landiolol. Le débit cérébral moyen dans l'artère cérébrale moyenne a augmenté de une à deux minutes après la stimulation électrique sans égard à l'usage de $B$-bloquants $(P<0,0 I)$. La durée des convulsions musculaires et électroencéphalographiques n'a pas été significativement modifiée par les $\beta$-bloquants.

Conclusion: Le landiolol supprime l'élévation de la fréquence cardiaque pendant la sismothérapie sans toucher la tension artérielle. Le débit cérébral dans l'artère cérébrale moyenne n'est pas modifiée par l'usage de l'esmolol ou du landiolol.

From the Departments of Anesthesiology* and Psychiatry†, Gunma University School of Medicine, Maebashi, Japan.

Address correspondence to: Dr. Shigeru Saito, Department of Anesthesiology, Gunma University Graduate School of Medicine, 3-39-22, Showamachi, Maebashi, 371-8511, Japan. Phone: +81-27-220-8454; Fax: +81-27-220-8473; E-mail: shigerus@showa.gunma-u.ac.jp This work is supported by Grant-in-Aids (Center of excellence 2004, Scientific Research Grant \#17591614 to S. Saito) from the Ministry of Education, Science and Culture of Japan.

Accepted for publication June 6, 2005.

Revision accepted July 6, 2005. 


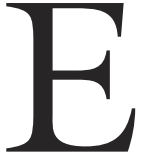

LECTROCONVULSIVE therapy (ECT) is effective for drug-therapy resistant severe depression. ${ }^{1,2}$ Anesthetic management using a muscle relaxant reduces the risks of ECT, such as bone fracture or soft tissue injury. However, hemodynamic changes in systemic or cerebral circulation are still concerns in the anesthetic management of ECT, especially when patients have cardiovascular or intracranial complications. ${ }^{2}$

In order to moderate the systemic hemodynamic fluctuations, recent guidelines have recommended use of anti-chronotropic drugs and/or anti-hypertensive medications to reduce the cardiovascular risks of ECT. ${ }^{2}$ An ultra-short acting $B$-adrenergic-blocking drug, esmolol, can be used as an anti-chronotropic drug. $^{3}$

During the sympathetic stimulation phase of ECT, cerebral blood flow is also augmented. Studies with transcranial Doppler ultra-sonography demonstrate an increase in cerebral blood flow velocity in a real-time manner. ${ }^{4,5}$ In one study, alprenolol partially attenuated cerebral blood flow elevation at a dose which prevents blood pressure (BP) elevation. ${ }^{6}$ Although esmolol is often used during ECT, there has been no report describing the effect of the ultra-short acting $ß$-adrenergic-blocking drugs on cerebral blood flow during ECT.

Recently, a new ultra-short acting $ß$-adrenergicblocking drug, landiolol, became clinically available. This drug is a more specific anti-chronotropic drug than esmolol, with minimal effect on BP. ${ }^{7}$ It is possible that landiolol is effective in ameliorating systemic and cerebral hemodynamic changes during ECT. Until now, there has been one report that demonstrated anti-chronotropic and hypotensive properties of landiolol in patients who received maintenance ECT with $1.5 \mathrm{mg} \cdot \mathrm{kg}^{-1}$ propofol and a sine-wave stimulator. ${ }^{8}$

The hypothesis examined in the present studies was that ultra-short acting $ß$-adrenergic-blocking drugs ameliorate systemic and cerebral hemodynamics immediately after the electrical stimulation. In addition, we compared the effects of two ultra-short acting $ß$-adrenergic-blocking drugs, esmolol and landiolol, on systemic and cerebral circulation during ECT. In the first study, dose-dependent effects of landiolol on heart rate $(\mathrm{HR})$ and $\mathrm{BP}$ were identified during ECT. In a second study, the effects of esmolol and landiolol on systemic and cerebral circulation were compared at equipotency. ${ }^{7}$

\section{Methods}

Patients

Written informed consent was obtained from each patient or, when direct communication with the patient was difficult, from the appropriate relative. The study protocol was approved by the Institutional Clinical Study Committee, which considers the ethics and legal aspects of clinical investigations. Electroconvulsive therapy was prescribed to 15 patients in the first study and 12 patients in the second study. Each patient received three doses of landiolol and vehicle solution (Study 1), or two types of $ß$-adrenergic-blocking drugs and vehicle solution (Study 2 ) in their sequential ECT sessions in a double blind crossover protocol. In order to detect a $20-\mathrm{mmHg}$ difference in mean BP or a 20 $\mathrm{cm} \cdot \mathrm{sec}^{-1}$ difference in mean cerebral blood flow velocity with a power greater than $80 \%$, we set the number of patients to 15 in the first study and 12 in the second study. The difference in the number of patients in the two studies is derived from the difference in standard deviation of mean BP and cerebral blood flow velocity in our previous studies. ${ }^{6,9}$

These patients were suffering from endogenous depression, and were in good physical health. No patient had cardiovascular or cerebrovascular complications, such as ischemic heart disease, hypertension, arrhythmia, cerebral infarction, intracranial aneurysm, arteriovenous malformation, or drug allergies. Patients under anti-hypertensive medication including $ß$-adrenergic-blocking drugs were excluded from the study subjects. Also, patients who had obstructive pulmonary disease such as bronchial asthma were excluded from the study. All patients were treated more than six times (three times per week at two-day intervals). The number of ECT sessions for each patient was determined by psychiatrists according to psychiatric symptoms, age, previous history of therapeutics, and the response to ECT. The data were obtained in the second to fifth ECT sessions in Study 1, and the second to fourth sessions in Study 2 in each case, after confirming that no adverse effects were reported in the previous ECT sessions. The selection of dosing $(0$, $0.125,0.25$, or $0.5 \mathrm{mg} \cdot \mathrm{kg}^{-1}$ ) or drugs (saline vehicle, esmolol $1.0 \mathrm{mg} \cdot \mathrm{kg}^{-1}$, or landiolol $0.5 \mathrm{mg} \cdot \mathrm{kg}^{-1}$ ) was determined using a random table. Except for the use of beta-blocking agents, anesthesia and electrical stimulation were identical in the ECT sessions where data were obtained.

\section{Anesthesia management and electrical stimulation}

To avoid an unfavourable parasympathetic reflex, atropine $0.01 \mathrm{mg} \cdot \mathrm{kg}^{-1} \mathrm{im}$ was given as premedication. Arterial BP was measured continuously at the right 
TABLE A Demographics

\begin{tabular}{lllll}
\hline & Age (yr) & Height $(\mathrm{cm})$ & Weight (kg) & Stimulus (\%) \\
\hline $\begin{array}{l}\text { Study 1 } \\
\text { ( }=15)\end{array}$ & $71 \pm 6$ & $160 \pm 12$ & $51 \pm 15$ & $48 \pm 21$ \\
$\begin{array}{l}\text { Study 2 } \\
(\mathrm{n}=12)\end{array}$ & $70 \pm 12$ & $159 \pm 12$ & $54 \pm 17$ & $53 \pm 16$ \\
\hline
\end{tabular}

Subjects in Study 1 and 2 were not overlapped.

TABLE B Seizure duration

\begin{tabular}{lll}
\hline & Muscular seizure (sec) & EEG seizure (sec) \\
\hline Study l & & \\
$\quad$ Landiolol & & \\
$\quad$ Vehicle & $34 \pm 9$ & $39 \pm 8$ \\
$0.125 \mathrm{mg} \cdot \mathrm{kg}^{-1}$ & $37 \pm 9$ & $42 \pm 8$ \\
$0.25 \mathrm{mg} \cdot \mathrm{kg}^{-1}$ & $34 \pm 7$ & $42 \pm 9$ \\
$0.5 \mathrm{mg} \cdot \mathrm{kg}^{-1}$ & $39 \pm 6$ & $44 \pm 7$ \\
& & \\
Study 2 & $38 \pm 11$ & $49 \pm 14$ \\
Vehicle & $37 \pm 8$ & $45 \pm 10$ \\
Esmolol $\left(1 \mathrm{mg} \cdot \mathrm{kg}^{-1}\right)$ & $49 \pm 16$ \\
Landiolol $\left(0.5 \mathrm{mg} \cdot \mathrm{kg}^{-1}\right)$ & $36 \pm 13$ & 49616
\end{tabular}

$\mathrm{EEG}=$ electroencephalography. There was no significant difference between groups.

radial artery using a tonometric BP monitor (CBM7000; Colin Co. Ltd., Komaki, Japan). Oxygen saturation was continuously monitored by a pulse oximeter (N-395; NELLCOR Puritan Bennett Inc. Lake Bluff, IL, USA). General anesthesia was induced with propofol $1 \mathrm{mg} \cdot \mathrm{kg}^{-1} i \nu$. Propofol was administered over $15 \mathrm{sec}$ through an indwelling iv catheter. After loss of consciousness, succinylcholine chloride $1 \mathrm{mg} \cdot \mathrm{kg}^{-1}$ $i v$ was administered and the patient was ventilated at a rate of 15 breath $\cdot \mathrm{min}^{-1}$ by a trained anesthesiologist using a facemask with $100 \%$ oxygen, and the end-tidal carbon dioxide measured at nostril was maintained between 35 to $40 \mathrm{mmHg}$. One minute after the succinylcholine injection, vehicle or one of the ultra-short acting $B$-adrenergic-blocking drugs dissolved in 10 $\mathrm{mL}$ of saline was injected over $30 \mathrm{sec}$. The syringe containing $\mathrm{B}$-adrenergic-blocking drugs or vehicle was labelled with a sequential number, so that the physicians could not identify the contents of the syringe. Three minutes after the succinylcholine injection, an electrical current was applied bilaterally. The dose of the electrical stimulation was determined during the first ECT session by stepwise increases in stimulus intensity to determine seizure threshold. The electrical stimulus was delivered by trained psychiatrists using an ECT-stimulator (THYMATRON ${ }^{\mathrm{TM}}$ DGx; Somatics Inc. Pleasanton, CA, USA). The efficacy of electrical stimulation was determined by the so-called tourniquet technique - that is by observation of convulsive movements of the distal leg, around which an inflated tourniquet was set to block the distribution of muscle relaxant. Electroencephalogram seizure duration was also measured by an electroencephalogram monitor set in the electrical stimulator.

\section{Measurement of cerebral blood flow velocity}

A transcranial-Doppler (TC2-64; EME Co. Ltd., Uberlingen, Germany) probe was adjusted to detect middle cerebral artery (MCA) flow from the right temporal side. The flow velocity at the MCA was measured using a $2-\mathrm{MHz}$ ultrasonic wave. The Doppler signals were obtained through the right temporal window at a depth of 45 to $55 \mathrm{~mm}$ from the surface. The signal quality was determined from both its characteristic high pitch sound and the waveform of the displayed sonogram. The velocity was calculated automatically by tracing the wave forms every five seconds.

\section{Data analysis}

The data are expressed as mean and the corresponding standard deviation. Data were compared by analysis of variance for repeated measures with a $P$ value $<0.05$ considered statistically significant. For comparison of each mean value, two-way analysis of variance was applied, and post-hoc testing was performed using Sheffe's method (StatView 5.0, SAS Institute Inc., NC, USA).

\section{Results}

Demographic characteristics of the patients are presented in Table A. The patients ranged from 54 to 81 $\mathrm{yr}$ of age in the first study, and from 40 to $80 \mathrm{yr}$ in the second study. Patients had been prescribed multiple psychiatric medications at various doses during their treatment, but were considered non-responsive to drug therapies. The medications were interrupted at least one day before the start of the ECT sessions. In both the first and second studies, there was no abortive electrical stimulation, and muscular and electroencephalographic seizure durations were not significantly different between groups (Table B). All patients in this study completed their scheduled ECT sessions (6-12 times) without any complication.

In the first study, HR increased one minute after the electrical stimulation in the vehicle treated group (Figure 1). No change in HR was observed in the patients who received landiolol 0.125 to $0.5 \mathrm{mg} \cdot \mathrm{kg}^{-1}$. There were significant differences between the vehicle treated group and the $0.25 \mathrm{mg} \cdot \mathrm{kg}^{-1}$ landiolol treated 


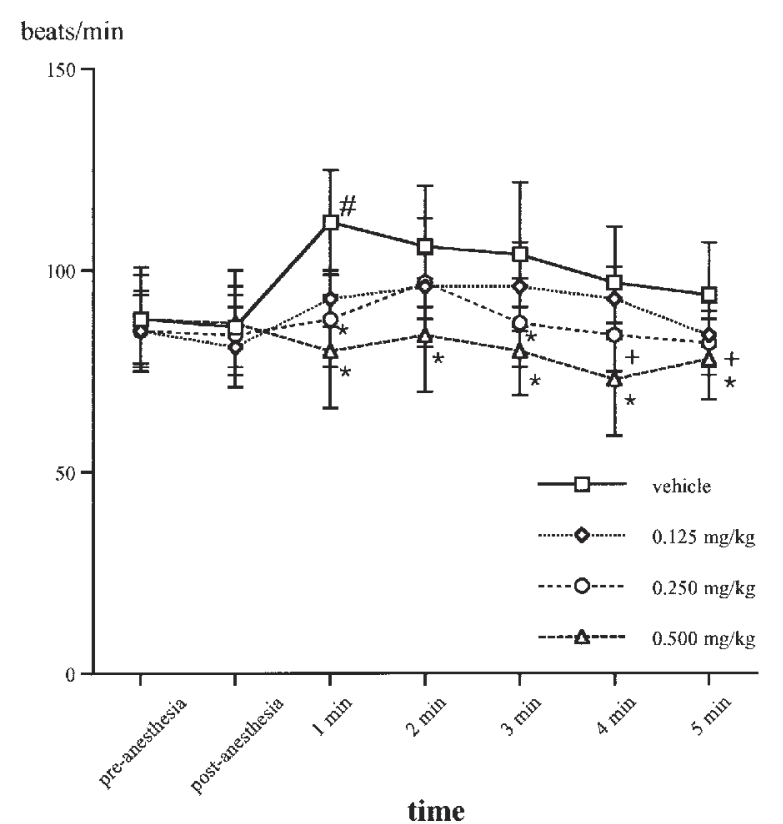

FIGURE 1 Heart rate after the administration of landiolol Heart rate increased one minute after electrical stimulation in the vehicle treated group $(\# P<0.01)$. No change in heart rate was observed in the patients who received landiolol 0.125 to $0.5 \mathrm{mg} \cdot \mathrm{kg}^{-1}$. Patients who received 0.25 to $0.5 \mathrm{mg} \cdot \mathrm{kg}^{-1}$ landiolol had lower mean heart rate values after the electrical stimulation compared to patients who received vehicle $\left({ }^{*} P<0.01\right.$ at one to five minutes after the electrical stimulation in the patients who received 0.5 $\mathrm{mg} \cdot \mathrm{kg}^{-1},{ }^{*} P<0.01$ at one and three minutes and $+P<0.05$ at four and five minutes after the stimulation in the patients who received $0.25 \mathrm{mg} \cdot \mathrm{kg}^{-1}$ ).

group $(P<0.05)$, and between the vehicle treated group and the $0.5 \mathrm{mg} \cdot \mathrm{kg}^{-1}$ landiolol-treated group $(P$ $<0.01)$. Patients who received 0.25 to $0.5 \mathrm{mg} \cdot \mathrm{kg}^{-1}$ landiolol had a lower HR after electrical stimulation when compared to the patients who received vehicle $(P<0.01$ at one to five minutes after the electrical stimulation in the patients who received $0.5 \mathrm{mg} \cdot \mathrm{kg}^{-1}$; $P<0.01$ at one and three minutes and $P<0.05$ at four and five minutes after the stimulation in the patients who received $\left.0.25 \mathrm{mg} \cdot \mathrm{kg}^{-1}\right)$. Blood pressure increased one minute after the stimulation in all groups, with no significant difference between the groups (Figure 2 ). No adverse effects, such as arrhythmia or severe bradycardia, were observed in association with the use of landiolol.

In the second study, HR increased at one minute after the stimulation in the vehicle treated group as

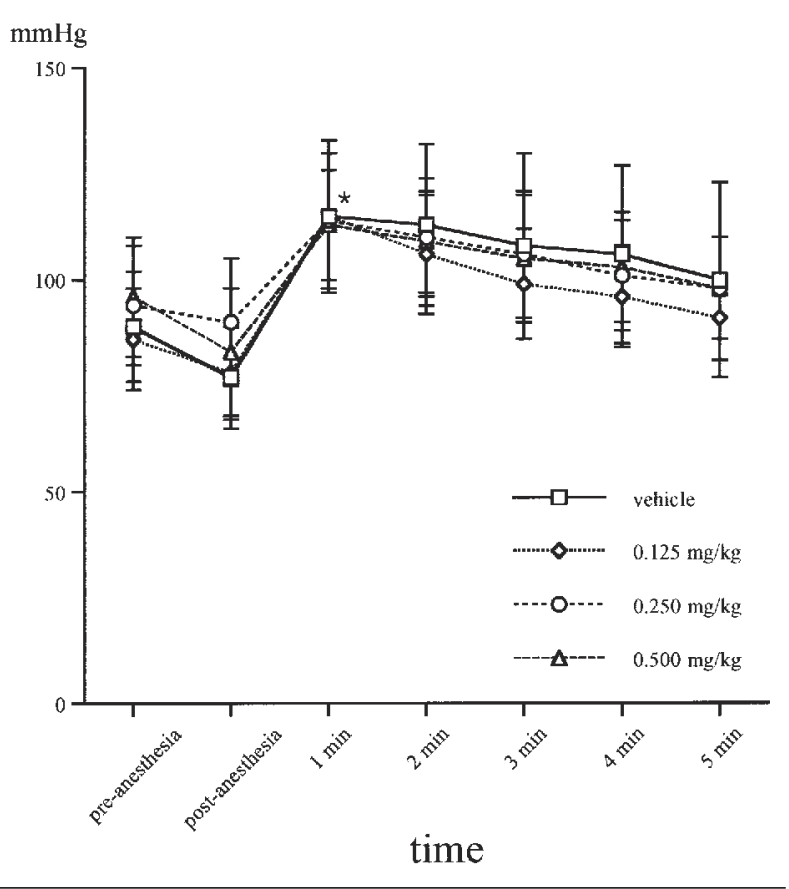

FIGURE 2 Blood pressure after the administration of landiolol

Blood pressure increased at one minute after stimulation in all groups $(P<0.05)$. There were no significant differences between the groups.

observed in Study 1 (Figure 3). There were no changes in HR compared to baseline values in either the esmolol or landiolol treated groups. Patients who received esmolol had a significantly lower HR one minute after stimulation, compared to patients who received vehicle $(P<0.05)$. Patients who received landiolol had a lower $\mathrm{HR}$ at one to four minutes after the stimulation, compared to the patients who received vehicle $(P<$ 0.01 ). Mean BP increased one minute after the stimulation in the patients who received vehicle or landiolol $(P<0.01)$, (Figure 4$)$. Mean BP in the patients who received esmolol did not change after the stimulation, and the value at one minute after the stimulation was lower than the corresponding value in the vehicle treated patients $(P<0.01)$.

Mean cerebral blood flow velocity at the MCA increased one to two minutes after ECT in the vehicle treated group $(P<0.01)$, (Figure 5$)$. The value in the esmolol or landiolol treated groups increased one to three minutes after the stimulation $(P<0.01$ at $1-2$ min after the stimulation, $P<0.05$ at 3 min after the stimulation), with no significant differences between groups. 


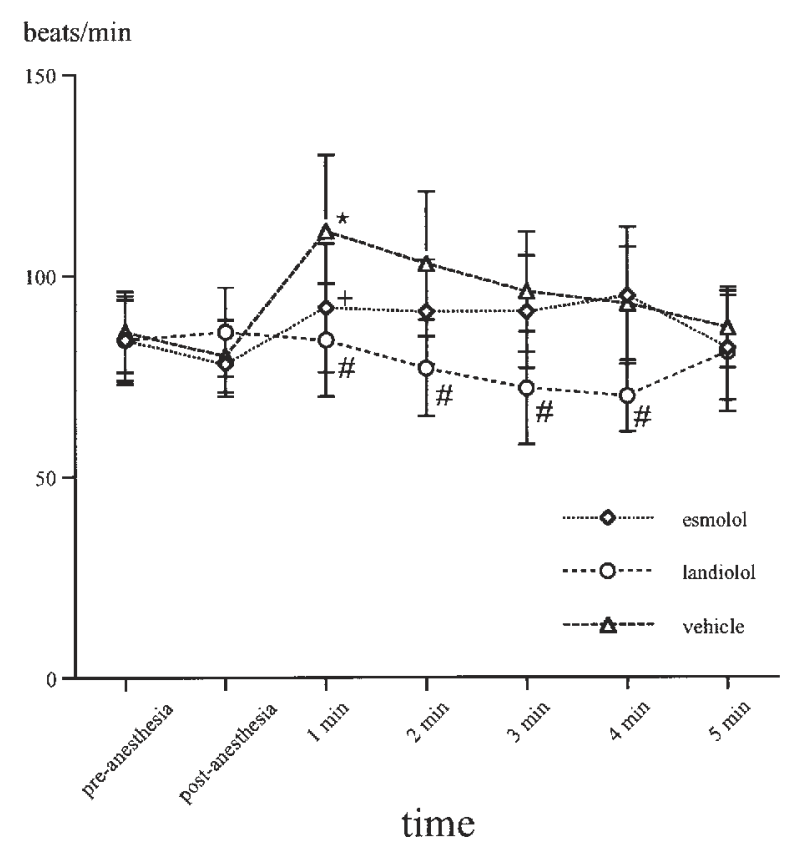

FIGURE 3 Heart rate after the administration of esmolol or landiolol

Heart rate increased at one minute after the stimulation in the vehicle treated group as observed in Study $1(P<0.01)$. Heart rate alteration was not observed in the patients who received esmolol or landiolol. Patients who received esmolol had a significantly lower heart rate at one minute after the stimulation compared to patients who received vehicle $(+P<0.05)$. Patients who received landiolol had lower heart rate values one to four minutes after the stimulation compared to patients who received vehicle $\left({ }^{*} P<0.01\right)$.

\section{Discussion}

In the present study, 0.25 to $0.5 \mathrm{mg} \cdot \mathrm{kg}^{-1}$ landiolol induced a lower HR after electrical stimulation compared to vehicle. Landiolol did not have significant effects on BP. Although HR was stabilized by 1.0 $\mathrm{mg} \cdot \mathrm{kg}^{-1}$ esmolol or $0.5 \mathrm{mg} \cdot \mathrm{kg}^{-1}$ landiolol, an increase in mean BP was ameliorated by esmolol, but not by landiolol. Mean cerebral blood flow velocity in the MCA increased one to two minutes after the electrical stimulation regardless of the use of $\beta$-adrenergicblocking drugs.

Heart rate and mean $\mathrm{BP}$ of the vehicle treated groups in the present study were compatible with our previous results. ${ }^{9-11}$ An increase in the cerebral blood flow velocity at one to three minutes after electrical stimulation was prolonged in this study compared to our previous study, where the increase subsided within

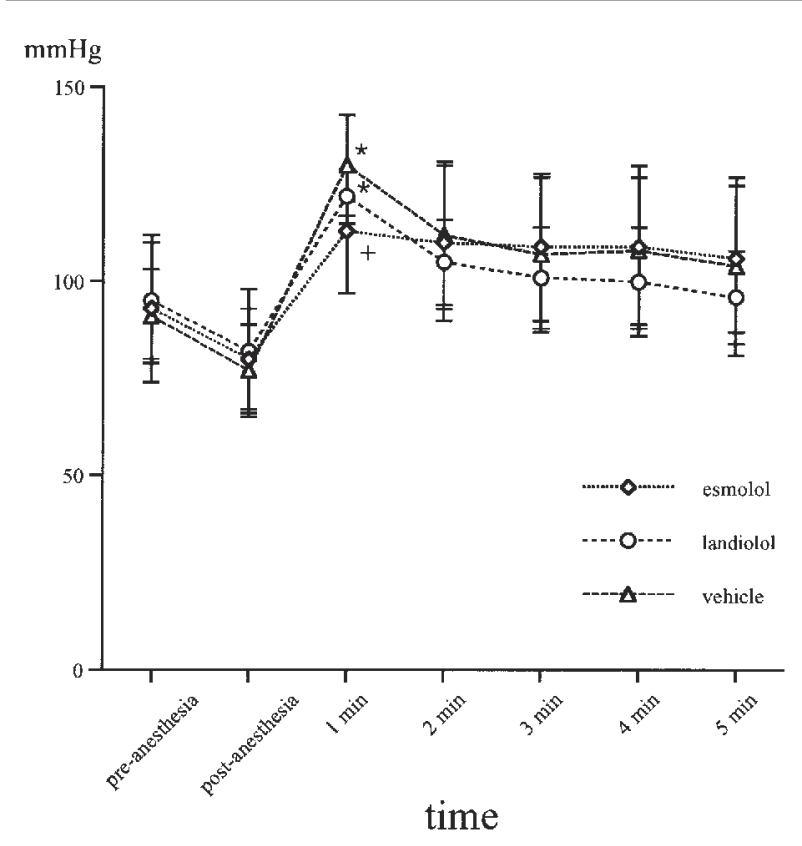

FIGURE 4 Blood pressure after the administration of esmolol or landiolol

Blood pressure increased at one minute after the stimulation in the patients who received vehicle or landiolol $\left({ }^{*} P<\right.$ $0.01)$. Blood pressure in the patients who received esmolol did not change after the stimulation and the value at one minute after the stimulation was lower than the corresponding value in the vehicle treated patients $(+P<0.01)$.

two minutes. ${ }^{9}$ The relatively greater age of patients, and possible cerebral atherosclerotic changes may have had been contributing factors in the present study.

During ECT, a parasympathetic discharge is stimulated at the beginning of seizure, thereafter sympathetic tones are elevated for five to ten minutes. ${ }^{1,12}$ In the sympathetic dominant phase, $\mathrm{HR}$ and $\mathrm{BP}$ are increased and cardiac oxygen demand is elevated. Both we ${ }^{13}$ and Bergsholm et al..$^{14}$ reported that the rate pressure product $(\mathrm{HR} \times \mathrm{SBP})$, an index of myocardial oxygen demand, is elevated by 50 to $400 \%$ immediately after the electrically induced seizure. When propofol is used as the induction drug, hemodynamic changes are minor compared to the effects observed with methohexital or thiopental. ${ }^{2,12}$ In some cases, temporary tachycardia is solely observed without hypertension.

In order to moderate systemic hemodynamic fluctuations, recent guidelines have recommended use 


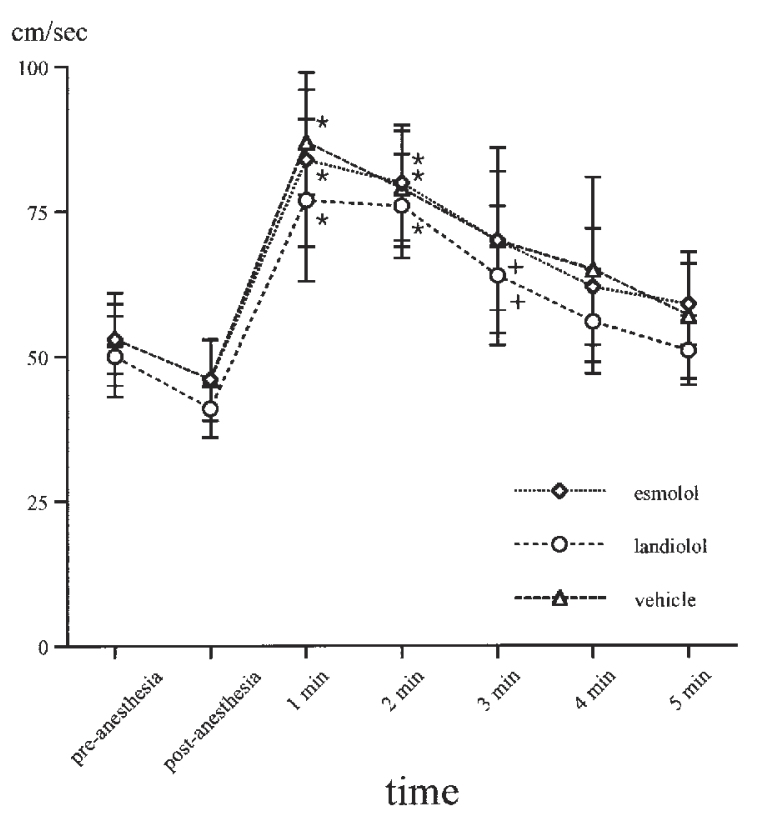

FIGURE 5 Cerebral blood flow velocity after the administration of esmolol or landiolol

Mean cerebral blood flow velocity of the middle cerebral artery increased at one to two minutes after stimulation in the vehicle treated group $\left({ }^{*} P<0.01\right)$. The value in the esmolol or landiolol treated group increased at one to three minutes after the stimulation $(* P<0.01$ at one to two minutes after the stimulation, $+P<0.05$ at three minutes after the stimulation). There were no significant differences between groups.

of anti-chronotropic drugs and/or anti-hypertensive medications to reduce the cardiovascular risks of ECT. ${ }^{2}$ The indication for these drugs may be greater when either methohexital or thiopental are used. An ultra-short acting $\beta$-adrenergic-blocking drug, esmolol, can be used as an anti-chronotropic agent. ${ }^{3}$ In some cases, however, BP elevation is not effectively prevented by esmolol. Several investigators recommend the combined use of two ß-adrenergic-blocking drugs, labetalol, which has combined $\alpha$ - and $\beta$ - blocking properties, and esmolol, to prevent both tachycardia and hypertension in patients with cardiovascular disease. ${ }^{15}$

Landiolol is a more specific anti-chronotropic $B$ adrenergic-blocking drug than esmolol, with minimal effects on BP. ${ }^{7}$ The carboxyl side branches contribute to its specific anti-chronotropism. ${ }^{16}$ Sasao et al. demonstrated that landiolol decreased HR more rapidly than esmolol without affecting $\mathrm{BP}$ in a rabbit model. ${ }^{7}$
In the present study, the effect on HR after the electrical stimulation was similar when comparing esmolol and landiolol. In contrast, a moderating effect on BP was observed only with esmolol. Kitamura $e t$ al. also reported that the action of landiolol was mostly antichronotropic, without anti-inotropic action in their study during tracheal intubation. ${ }^{17}$ These phenomena may imply that the action of landiolol is purely anti-chronotropic. Recently, however, Sakamoto et al. demonstrated hypotensive properties of landiolol in patients who received maintenance ECT with 1.5 $\mathrm{mg} \cdot \mathrm{kg}^{-1}$ propofol and a sine-wave stimulator. ${ }^{8}$ It is possible that landiolol has some hypotensive action when administered with higher anesthetic doses.

In a clinical study examining the hemodynamic effects of landiolol during tracheal intubation, 0.25 to $0.5 \mathrm{mg} \cdot \mathrm{kg}^{-1}$ landiolol effectively prevented tachycardia during intubation. ${ }^{17}$ Based upon the results of this study, we examined the systemic hemodynamic effects of landiolol over a dose range of 0.125 to 0.5 $\mathrm{mg} \cdot \mathrm{kg}^{-1}$. The results of the present study demonstrate that landiolol can be used safely and effectively in attenuating tachycardia in response to ECT under propofol anesthesia. According to reports by Sasao et al., the anti-chronotropic potency of landiolol was approximately double that of esmolol in an in vivo rabbit model. ${ }^{7}$ The recommended dose of esmolol for ECT is approximately $\mathrm{l} \mathrm{mg} \cdot \mathrm{kg}^{-1},{ }^{2,12}$ suggesting an effective dose of 0.25 to $0.5 \mathrm{mg} \cdot \mathrm{kg}^{-1}$ landiolol for this indication. We observed that 0.25 to $0.5 \mathrm{mg} \cdot \mathrm{kg}^{-1}$ landiolol and $1.0 \mathrm{mg} \cdot \mathrm{kg}^{-1}$ esmolol exhibit a similar anti-chronotropic response one minute after the electrical stimulation.

The anti-chronotropic action of landiolol is slightly longer than that of esmolol in the canine isolated heart preparation. ${ }^{18}$ In our study, HR in the landiolol treated group was lower than that of the vehicle treated group for four minutes, while the HR in the esmolol treated group was lower than that of the vehicle group for one minute. This difference might imply that the anti-chronotropic action of landiolol is longer than that of esmolol.

There have been several reports describing ischemic cardiac complications during ECT. ${ }^{19,20}$ Usually, both anti-chronotropic and anti-inotropic actions are required for hemodynamic stabilization during ECT under barbiturate anesthesia. However, in the patients with ischemic heart disease and compromised cardiac function, pure anti-chronotropic action without antiinotropic action may be required. ${ }^{21}$ Landiolol might be suitable when ECT is scheduled for patients with low cardiac output syndrome accompanied by ischemic heart disease, to whom pure anti-chronotropic 
action without anti-inotropic effect is advantageous. Also, when tachycardia is an isolated hemodynamic manifestation during ECT, landiolol might be superior to other $\beta$-adrenergic-blocking drugs. Since this study was designed to identify the effects of landiolol and esmolol in patients without cardiovascular complications, further studies and more clinical experience are required to determine what types of patients are most suitable to these $B$-adrenergic-blocking drugs.

Although catastrophic cerebral complications in association with ECT are rare, careful management is recommended when patients have an intracranial mass or aneurysm. ${ }^{2}$ Previously, we reported that the use of anti-hypertensive drugs influences cerebral blood flow, and that the effect on cerebral blood flow varies amongst the anti-hypertensive drugs. Effects of ultra-short acting $B$-adrenergic-blocking drugs on cerebral blood flow during ECT have not been examined. However, there are several reports that examined effects of esmolol on cerebral blood flow in other clinical settings. Strebel et al. demonstrated that an increase in cerebral blood flow velocity induced by ketamine administration could not be blocked by esmolol. ${ }^{22}$ Heinke et al. reported that esmolol does not affect a cerebral blood flow increase after $B$-adrenergic stimulation. ${ }^{23}$ In accordance with these reports, in our present study, both esmolol and landiolol had minimal effects on cerebral blood flow velocity during ECT. In contrast, Grillo et al. demonstrated that an increase in cerebral blood flow during emergence from neurosurgical anesthesia was blunted by continuous esmolol infusion. ${ }^{24}$ The effect of ultra-short acting $ß$-adrenergic-blocking drugs on cerebral blood flow might vary depending on the clinical setting.

In the present study, neither esmolol nor landiolol had a significant effect on seizure duration. Sakamoto et al. also demonstrated that landiolol at $0.1 \mathrm{mg} \cdot \mathrm{kg}^{-1}$ did not affect seizure duration in ECT. ${ }^{8}$ These results were compatible with the report by Weinger et al. that demonstrated a minimal effect of esmolol on seizure duration. ${ }^{25}$ However, van den Broek et al. ${ }^{26}$ reported relatively short seizures when esmolol was used during ECT. Differences with respect to patient characteristics, use of opioids, and the dose and type of anesthetics might explain the varying results in these clinical studies.

In conclusion, the new ultra-short acting $ß$-adrenergic-blocking drug, landiolol, effectively suppressed HR elevation after the electrical stimulation of ECT. The effect on BP was minimal and less than that of esmolol. Cerebral blood flow velocity in the MCA was not affected by the use of either esmolol or landiolol.

\section{Acknowledgements}

The authors thank Professor Mikuni Masahiko (Department of Psychiatry, Gunma University) for his cooperation in this study, and Dr. Shaphan Hardy for English editing.

\section{References}

1 Gaines $G Y 3^{\text {rd }}$, Rees DI. Anesthetic considerations for electroconvulsive therapy. South Med J 1992; 85: 469-82.

2 Weiner RD, Coffey CE, Fochtmann LJ, et al. The Practice of Electroconvulsive Therapy: Recommendations for Treatment, Training, and Privileging, 2nd ed. A Task Force Report of the American Psychiatric Association. Washington DC: American Psychiatric Association; 2001.

3 Howie MB, Hiestand DC, Zvara DA, Kim PY, McSweeney $T D$, Coffman JA. Defining the dose range for esmolol used in electroconvulsive therapy hemodynamic attenuation. Anesth Analg 1992; 75: 805-10.

4 Saito S, Yoshikawa D, Nishihara F, et al. The cerebral hemodynamic response to electrically induced seizures in man. Brain Res 1995; 673: 93-100.

5 Vollmer-Haase J, Folkerts HW, Haase CG, Deppe M, Ringelstein EB. Cerebral hemodynamics during electrically induced seizures. Neuroreport 1998; 9: 407-10.

6 Saito S, Kadoi Y, Iriuchijima N, et al. Reduction of cerebral hyperemia with anti-hypertensive medication after electroconvulsive therapy. Can J Anesth 2000; 47: 767-74.

7 Sasao J, Tarver SD, Kindscher JD, Taneyama C, Benson $K T$, Goto $H$. In rabbits, landiolol, a new ultra-short acting beta-blocker, exerts a more potent negative chronotropic effect and less effect on blood pressure than esmolol. Can J Anesth 2001; 48: 985-9.

8 Sakamoto A, Ogawa R, Suzuki H, Kimura M, Okubo $\Upsilon$, Fujiya $T$. Landiolol attenuates acute hemodynamic responses but does not reduce seizure duration during maintenance elelctroconvulsive therapy. Psychiatry Clin Neurosci 2004; 58: 630-5.

9 Saito S, Kadoi $\Upsilon$, Nara T, et al. The comparative effects of propofol versus thiopental on middle cerebral artery blood flow velocity during electroconvulsive therapy. Anesth Analg 2000; 91: 1531-6.

10 Kadoi $\Upsilon$, Saito S, Seki S, Ide M, Morita T, Goto F. Electroconvulsive therapy impairs systolic performance of the left ventricle. Can J Anesth 2001; 48: 405-8.

11 Saito S, Kadoi $\Upsilon$, Nibishara F, Aso C, Goto F. End-tidal carbon dioxide monitoring stabilized hemodynamic changes during ECT. J ECT 2003; 19: 26-30.

12 Ding Z, White PF. Anesthesia for electroconvulsive therapy. Anesth Analg 2002; 94: 1351-64.

13 Nishibara F, Saito S, Tobe M, Harada N, Kadoi Y, Goto $F$. Hemodynamic changes during electroconvulsive therapy under propofol anesthesia. J Anesth 2002; 16: 332-5. 
14 Bergsholm P, Bleie H, Gran L, d'Elia G. Cardiovascular response and seizure duration as determined by electroencephalography during unilateral electroconvulsive therapy. Acta Psychiatr Scand 1993; 88: 25-8.

15 Weinger MB, Partridge BL, Hauger R, Mirow A, Brown $M$. Prevention of the cardiovascular and neuroendocrine response to electroconvulsive therapy: II. Effects of pretreatment regimens on catecholamines, ACTH, vasopressin, and cortisol. Anesth Analg 1991; 73: 563-9.

16 Iguchi S, Iwamura $H$, Nishizaki $M$, et al. Development of a highly cardioselective ultra short-acting betablocker, ONO-1101. Chem Pharm Bull 1992; 40: 1462-9.

17 Kitamura A, Sakamoto A, Inoue T, Ogawa R. Efficacy of an ultrashort-acting beta-adrenoceptor blocker (ONO-1101) in attenuating cardiovascular responses to endotracheal intubation. Eur J Clin Pharmacol 1997; 51: 467-71.

18 Motomura S, Hagihara A, Narumi $\Upsilon$, Hashimoto $K$. Time course of a new ultrashort-acting betaadrenoceptor-blocking drug, ONO-1101: comparison with those of esmolol and propranolol by using the canine isolated, blood-perfused heart preparations. J Cardiovasc Pharmacol 1998; 31: 431-40.

19 Lopez-Gomez D, Sanchez-Corral MA, Cobo JV, Jara $F$, Esplugas E. Myocardial infarction after electroconvulsive therapy (Spanish). Rev Esp Cardiol 1999; 52: 536-8.

20 Ali PB, Tidmarsh MD. Cardiac rupture during electroconvulsive therapy. Anaesthesia 1997; 52: 884-6.

21 Kirshenbaum JM, Kloner RA, Antman EM, Braunwald $E$. Use of an ultra short-acting beta-blocker in patients with acute myocardial ischemia. Circulation 1985; 72 : 873-80.

22 Strebel S, Kaufmann M, Maitre L, Schaefer HG. Effects of ketamine on cerebral blood flow velocity in humans. Influence of pretreatment with midazolam or esmolol. Anaesthesia 1995; 50: 223-8.

23 Heinke W, Zysset S, Hund-Georgiadis M, Olthoff D, von Cramon DY. The effect of esmolol on cerebral blood flow, cerebral vasoreactivity, and cognitive performance: a functional magnetic resonance imaging study. Anesthesiology 2005; 102: 41-50.

24 Grillo P, Bruder N, Auquier P, Pellissier D, Gouin $F$. Esmolol blunts the cerebral blood flow velocity increase during emergence from anesthesia in neurosurgical patients. Anesth Analg 2003; 96: 11459.

25 Weinger $M B$, Partridge BL, Hauger R, Mirow A. Prevention of the cardiovascular and neuroendocrine response to electroconvulsive therapy: I. Effectiveness of pretreatment regimens on hemodynamics. Anesth Analg 1991; 73: 556-62.

26 van den Broek WW, Leentjens AF, Mulder PG, Kusuma A, Bruijn JA. Low-dose esmolol bolus reduces seizure duration during electroconvulsive therapy: a doubleblind, placebo-controlled study. Br J Anaesth 1999; 83: $271-4$. 